\title{
DEVELOPING AND VALIDATING THE IP-SRP (IMPACT OF PANDEMICS OVER SURGICAL RESIDENCY PROGRAM) TOOL IN A TERTIARY CARE HOSPITAL SETTING
}

\author{
Farooq Ahmed ${ }^{1}$, Sajjad Ali $^{2}$, Lubna Kashif ${ }^{3}$, Ahsan Sethi ${ }^{4}$, Usman Mahboob ${ }^{5}$, Kashif Anwar \\ 1,3Department of Medical Education, Khyber Medical College, Peshawar - Pakistan \\ ²Department of Paediatric Surgery, Khyber Teaching Hospital, Peshawar - Pakistan \\ 4,5Department of Medical Education, Khyber Medical University, Peshawar - Pakistan \\ ${ }^{6}$ Department of Anaesthesia, Peshawar Institute of Cardiology, Peshawar - Pakistan
}

\begin{abstract}
Objective: To develop and validate a survey to be used for determining the impact of pandemics on residents working in Surgical and allied disciplines in a teaching hospital.

Material and Methods: A survey tool was developed and reviewed according to AMEE guide 87, Khyber Medical College, Peshawar. After face, content and construct validation, internal consistency and test-retest reliability were calculated by Cronbach alpha on standardized items and Pearson "r" respectively with the help of SPSS-25.

Results: During the process, a 28-item survey tool was reduced to 16 items. The items were grouped under 5 sections namely: preliminary data, skills, academic activities, impact over research activities and impact over examination preparations and schedules. The responses of all sections were recorded in the Likert scale (with options from 4-6) while one sections response was either "yes/no/unsure. The results of the pilot study revealed Cronbach's alpha of 0.7 and Pearson " $r$ " for test-retest reliability on all items as 0.7 to 1 .
\end{abstract}

Conclusion: IP-SRP survey is a new validated tool with good validity and reliability that can be used by healthcare professionals in times of pandemics, calamities and natural disasters that occur locally, regionally or globally.

Keywords: IP-SRP survey, skills, academic, research, examination.

This article may be cited as: Ahmed F, Ali S, Kashif L, Sethi A, Mahboob U, Anwar K. Developing and validating the IP-SRP (Impact of Pandemics over Surgical Residency Program) tool in a tertiary care hospital setting. J Med Sci 2021 January;29(1):17-20

\section{INTRODUCTION}

Natural disasters in the form of earthquakes, tsunamis have affected everyday life throughout the world. But the recently developed pandemic of COVID-19 has affected human life across the globe in all aspects notably, economics, education, and health ${ }^{1}$. This is also true for postgraduate residency programs in healthcare in all disciplines. The number of out-patients has declined significantly throughout the hospitals in the country and similarly, the number of surgeries (both major and minor) performed in these hospitals has also declined. Similarly, ward round teachings, research activities, seminars, workshops, and conferences have been halted due to the pandemic and

\section{Correspondence}

Dr. Lubna Kashif

Senior Lecturer

Department of Medical Education

Khyber Medical College, Peshawar-Pakistan

Email: lubna148@live.ie

Cell: +92-321-9179191

Date received: $02-07-2020$

Date revised: $05-01-2021$

Date accepted: $28-01-2021$ some of these activities have been converted into virtual platforms. There is meagre exposure of postgraduate students to patients that have resulted in reduced exposure of students to patient encounters, surgeries, and other activities like presentations skills and research activities. No one knows the extent of this pandemic, but everyone knows the duration of students'training ${ }^{2}$. Which is being affected by lack of teaching and training that will ultimately affect the quality of specialists produced with limited skills and attitudes regarding their speciality.

The magnitude of the impact of the pandemics and other natural calamities especially COVID-19 over healthcare education needs to be measured explicitly so that corrective measures can be taken post-pandemic. So far, no method of measurement has been identified or proposed to calculate the true impact of it throughout the world. One method of measuring it is with the help of developing a survey or qualitative analysis. These measures need to be validated to enhance their worth, a new survey was developed and validated which is termed IP-SRP (Impact of Pandemics over Surgical Residency Program). Which will help to measure the impact of disasters and 
Developing And Validating The Ip-Srp (Impact Of Pandemics Over Surgical Residency Program) Tool In A Tertiary Care...

pandemics, especially COVID-19, over postgraduate surgical residency program in teaching hospitals. The survey can be utilized in other residency programs related to medicine, dentistry, allied health, and nursing with or without minor modifications. This study aims to describe the steps of developing and validating the IP-SRP survey in a teaching hospital setting to be used later for its defined purpose.

\section{MATERIALS AND METHODS}

We developed and validated the IP-SRP survey in the month of July 2020, in the department of medical education in collaboration with the surgical and allied disciplines of Khyber Teaching Hospital, which is a 1600 bedded tertiary care hospital in the Khyber Pakhtunkhwa province of Pakistan. The IREB (Institutional Research and Ethical Review Board) of the institution approved the proposal of the research. Survey validation: FA and SA did an extensive literature search to find studies, surveys, and other materials related to the topic. In the first instance, SA presented a tool consisting of 28 items with yes/no responses. After extensive discussion, FA and SA modified the tool by reducing the number of items to 16 , with 5 point Likert scale responses (A-E), where A means $100 \%$, B means $75 \%$, C means 50\%, D means $25 \%$, and $\mathrm{E}$ as $0 \%$. The IP-SRP survey was divided into 5 sections and one open-ended question at the end. The first section consisted of the name (optional), gender, specialty, name of the hospital, and year of the residency program. The next section consisted of 4 domains; i.e. Skills (containing 4 items), Academic activities (2 items), impact over research activities (3 items), and impact over examination preparations and schedules (4 options). The responses of this section are in "yes/no/not applicable.

The survey tool was sent to 2 medical educationists with doctorate degrees via email to check for content and construct validity. After their feedback, we modified the items construct from a question type to a narrative type and dropped one item from section 4 . We presented the survey form to a subject experts in a meeting and the final changes were made after the deliberations as shown in results.

Reliability of a pilot survey enable refinement of the item list and demonstration of construct validity ${ }^{3}$. We developed Google forms for the IP-SRP tool to be distributed amongst surgical residents as part of pilot testing. No financial or other incentives were provided to the residents for participation. We calculated Reliability using Cronbach alpha on standardized items and test-retest reliability using Pearson " $r$ " keeping the p-value as 0.05 or less.

\section{RESULTS}

We performed a literature review to find the available tool to determine the impact of pandemics over residency programs in healthcare. Google Scholar and ERIC (Educational Resource and Information Center) were used as databases. The search statements used during the literature search were, 1) Tools to assess the impact of pandemic over healthcare residency programs 2) Surveys to assess the impact of COVID-19 pandemics on healthcare residency programs. A total of 5 recent articles published were reviewed to develop and validate our tool (see table-1 for details)

Item related to academics and research were grouped into "before the pandemic and during pandemic" and were converted from percentage style of Likert scale responses to "none, rare, occasional and frequent". Items related to research were converted to a "yes and no" for the first item and 6 points Likert scale for the rest of the items. For items related to assessment, 4 points Likert scale "not confident, less confident, confident and very confident" was developed along with an open-ended question about the examination preparations. After all these modifications, the survey was considered fit for pilot testing. Upon sending the survey via Google forms to 35 residents belonging to different surgical specialties and having experience of year 1-4, we received responses from 19 participants. Those 19 participants were re-surveyed the next day to check test-retest reliability. The results of the survey are mentioned in the next section, while a reliability coefficient (Cronbach alpha) was calculated via SPSS-25 and was found to be 0.7 for standardized items. For test-retest reliability, Pearson " $r$ " ranged from 0.7-1 (see table-2).

We all authors decided to replace the name of CPSP (College of Physicians and Surgeons of Pakistan) with the assessment body, the name of IMM (intermediate module) with intermediate examination for a residency program, and Part-2 examination (part-2 examination of FCPS) with exit examination of the residency program. These names were used in section 4 (assessment) of the proforma. This was done with the intent that not all residents are the students of CPSP, as some students belong to institutions other than that. The results of the last open-ended questions were analyzed thematically, where 3 themes were derived. These were related to 1) deficiency in clinical training, 2) deficient knowledge and 3) lack of educational environment in a clinical setting.

\section{DISCUSSION}

We have described the development and validation of an instrument that can measure the impact of

Table 1: Literature search databases and number of articles retrieved

\begin{tabular}{|c|c|c|c|c|}
\hline Database used & $\begin{array}{c}\text { Articles retrieved after } \\
\text { search statement-1 }\end{array}$ & $\begin{array}{c}\text { Articles retrieved after } \\
\text { search statement-2 }\end{array}$ & $\begin{array}{c}\text { Abstracts read } \\
\text { Final articles included } \\
\text { for study }\end{array}$ \\
\hline ERIC & 1012 & 197 & 13 & 2 \\
\hline Google Scholar & 17200 & 1400 & 15 & 3 \\
\hline Total & 18212 & 1597 & 28 & 5 \\
\hline
\end{tabular}


Developing And Validating The Ip-Srp (Impact Of Pandemics Over Surgical Residency Program) Tool In A Tertiary Care...

Table 1: Details of inter-item correlation of different items used

\begin{tabular}{|c|c|c|}
\hline Domains & Items & $\begin{array}{l}\text { Inter-item } \\
\text { correlation } \\
\quad(r)\end{array}$ \\
\hline \multirow[t]{8}{*}{$\begin{array}{l}\text { Surgical } \\
\text { skills }\end{array}$} & $\begin{array}{c}\text { Opportunities to observe } \\
\text { surgeries before the pandemic }\end{array}$ & $1 * *$ \\
\hline & $\begin{array}{c}\text { Opportunities to observe } \\
\text { surgeries during the pandemic }\end{array}$ & $0.7^{\star \star}$ \\
\hline & $\begin{array}{c}\text { Opportunities to assist surgeries } \\
\text { before the pandemic }\end{array}$ & $0.9 * *$ \\
\hline & $\begin{array}{c}\text { Opportunities to assist surgeries } \\
\text { during the pandemic }\end{array}$ & $0.9 * *$ \\
\hline & $\begin{array}{l}\text { Opportunities to perform } \\
\text { surgeries under supervision } \\
\text { before the pandemic }\end{array}$ & $0.9^{* \star}$ \\
\hline & $\begin{array}{l}\text { Opportunities to perform } \\
\text { surgeries under supervision } \\
\text { during the pandemic }\end{array}$ & $1 * *$ \\
\hline & $\begin{array}{l}\text { Opportunities to perform } \\
\text { surgeries independently before } \\
\text { the pandemic }\end{array}$ & $1 * *$ \\
\hline & $\begin{array}{l}\text { Opportunities to perform } \\
\text { surgeries independently during } \\
\text { the pandemic }\end{array}$ & $0.9^{* *}$ \\
\hline \multirow[t]{4}{*}{ Academics } & $\begin{array}{l}\text { Frequency of academic ward } \\
\text { rounds before the pandemic }\end{array}$ & $0.7^{\star \star}$ \\
\hline & $\begin{array}{l}\text { Frequency of academic ward } \\
\text { rounds during the pandemic }\end{array}$ & $0.7^{* *}$ \\
\hline & $\begin{array}{l}\text { Frequency of workshops/ } \\
\text { seminars attended before the } \\
\text { pandemic }\end{array}$ & $1^{* *}$ \\
\hline & $\begin{array}{l}\text { Frequency of academic ward } \\
\text { rounds during the pandemic }\end{array}$ & $1 * *$ \\
\hline \multirow[t]{3}{*}{$\begin{array}{l}\text { Research } \\
\text { activities }\end{array}$} & $\begin{array}{l}\text { Has the pandemic delayed } \\
\text { your synopsis/proposal writing/ } \\
\text { acceptance? }\end{array}$ & $1^{* *}$ \\
\hline & $\begin{array}{l}\text { How much has your data } \\
\text { collection been affected by } \\
\text { changes in hospital protocols } \\
\text { during the pandemic? }\end{array}$ & $1^{* *}$ \\
\hline & $\begin{array}{l}\text { How much has your } \\
\text { dissertation/thesis writing been } \\
\text { affected by changes in hospital } \\
\text { protocols during the pandemic }\end{array}$ & $0.9 * *$ \\
\hline Assessments & $\begin{array}{l}\text { How confident are you that your } \\
\text { final assessment (IMM / FCPS } \\
\text { examination) will take place in } \\
\text { time despite the pandemic? }\end{array}$ & $0.9^{* *}$ \\
\hline
\end{tabular}

pandemics and calamities over residency programs in healthcare settings, especially in surgical practices. This survey tool was developed at a time where the COVID-19 pandemic is rampant throughout the globe, but it can also be used in localities where such calamities and natural disasters happen that can affect the continuity of education and healthcare. The explicit process of face, content, and construct validation and adequate reliability coefficient signifies its utility to be used in such circumstances. Al- though the Delphi technique ${ }^{4}$ was not used in the generation of the tool, the input of subject experts, reviewers of the tools, and feedback of the pilot study participants cannot be underestimated. A Cronbach alpha of 0.7 or more for standardized items and its consistency during test-retest analysis highlights the value of this tool to be used when any surgical residency program is interrupted by calamities and disasters like the COVID-19 pandemic.

Another tool was recently developed and used amongst cardiothoracic trainees in the United Kingdom ${ }^{5}$ to find out the impact of the COVID-19 pandemic over the cardiothoracic residency program. Which was a 31item newly validated questionnaire distributed amongst 118 trainees. It assessed the pre-COVID and post-COVID training in terms of patient care, research activities, and educational activities. This is different from our survey as we explored the perceptions of students in quantitative terms during COVID-19 only. We did not incorporate questions in all items, which could have compared the pre and post COVID-19 situations. Although, we compared the domain of clinical skills and academics before and during the pandemic only, ${ }^{6,7}$. Another survey conducted in India ${ }^{8}$, to assess the impact of COVID 19 on Ophthalmology training, was published recently. That survey tool was a non-validated self-designed 21 item tool that focused over theoretical teaching, practical surgical training, mental wellbeing and small group educational activities ${ }^{9}$. A nationwide survey was conducted in Italy to determine the impact of COVID-19 over Gastroenterology services and training, which revealed that clinical, endoscopic and patient management services have impaired drastically due to the pandemic ${ }^{10}$. A world-wide survey amongst neurosurgeons revealed that non-emergency neurosurgical operations have been significantly postponed due to the pandemic ${ }^{11}$. Similarly, the impact of this pandemic over dentistry programs, spine surgical specialties, urology, nursing programs and other allied health disciplines had been determined using different types of survey instruments ${ }^{12,13,14,15}$. All surveys already mentioned used tools, which were used for the first time and were self-designed. Our tool is different from others as it looks explicit, short, focused, and only concentrates on surgical skills, academics, research, and assessments. Our survey does not take into account many of the items included in other studies mentioned here because of which, we think this tool can be used in most of other clinical disciplines also.

One of the limitations of this research seems to be a small sample size during pilot testing. This sample size was based on a study published in the Saudi Journal of Anaesthesia which highlights the need of a preliminary pilot testing during validating and translating a survey instrument ${ }^{11}$. 


\section{CONCLUSION}

IP-SRP is a new tool with good validity and reliability that can be used by healthcare professionals in times of pandemics, calamities, and natural disasters that strike the world population locally, regionally, or globally. Further pilot testing at multiple centers throughout the world is needed to enhance the validity and reliability of this tool.

\section{REFERENCES}

1. Chew N., Lee L.G., Tan B.Y., Jing M., Goh Y., Ngiam N., Yeo L., Ahmad A., Khan F.A., Shanmugam G., Sharma A., Komalkumar R.N., Meenakshi R.V., Shah K., Patel B., Chan B.P.L., Sunny S., Chandra B., Ong J., Paliwal P., Wong L., Sagayanathan R., Chen J.T., Ng A., Teoh H.L., Dr Tsivgoulis G., Ho C.S.H., Ho R., Sharma V. A multinational, multicentre study on the psychological outcomes and associated physical symptoms amongst healthcare workers during COVID-19 outbreak. Brain Behav. Immun. 2020

2. Ehizogie Edigin, Precious Obehi Eseaton, Hafeez Shaka, Pius Ehiremen Ojemolon, Iriagbonse Rotimi Asemota and Emmanuel Akuna. Impact of COVID-19 pandemic on medical postgraduate training in the United States. Med Edu Online 2020; 25:1, 1774318, DOI: 10.1080/10872981.2020.1774318

3. Beavers AS, Lounsbury JW, Richards JK, Huck SW, Skolits GJ, Esquivel SL. Practical considerations for using exploratory factor analysis in educational research. Prac Assessment, Res Eval 2013; 18: 1-13. Available from URL: http:// pareonline.net/pdf/v18n6.pdf

4. Alvin MD, George E, Deng F, et al. The impact of COVID-19 on radiology trainees. Radiology 2020. doi:10.1148/radiol.2020201222. Published Online March 27. Accessed March 29, 2020

5. Caruana EJ, Patel A, Kendall S, Rathinam S. Impact of Covid-19 on training and wellbeing in subspecialty surgery: a national survey of cardiothoracic trainees in the United Kingdom. J Thorac Cardiovasc Surg. 2020. IN PRESS.

6. Kogan M, Klein SE, Hannon CP, Nolte MT. Orthopedic education during the COVID-19 pandemic. J Am Acad Orthop Surg. 2020;28(11): e456-e464.

7. Sidhu NS, Clissold E. Developing and validating a tool for measuring the educational environment in clinical anesthesia. Canad J Anesth. 2018 Nov 1;65(11):1228-39.

8. Mishra D, Nair AG, Gandhi RA, Gogate PJ, Mathur S, Bhushan P, Srivastav T, Singh H, Sinha BP, Singh MK. The impact of COVID-19 related lockdown on ophthalmology training programs in India-Outcomes of a survey. India J Ophtha. 2020 Jun 1;68(6):999.

9. Maida M., Sferrazza S., Savarino E. Impact of COVID-19 pandemic on Gastroenterology Divisions in Italy: a national survey. Dig Liver Dis. May 2020 doi: 10.1016/j. dld.2020.05.017.
10. Jean WC, Ironside NT, Sack KD, Felbaum DR, Syed HR. The impact of COVID-19 on neurosurgeons and the strategy for triaging non-emergent operations: a global neurosurgery study. Acta neurochirurgica. 2020 Apr 21:1-2.

11. Tsang S, Royse CF, Terkawi AS. Guidelines for developing, translating, and validating a questionnaire in perioperative and pain medicine. Saudi J anesth. 2017 May;11(Suppl 1):S80.

12. Huntley RE, Ludwig DC, Dillon JK. The Early Effect of COVID-19 on Oral and Maxillofacial Surgery Residency Training-Results from a National Survey. J Oral and Maxillofacial Surg. 2020 May 30. DOI: https://doi. org/10.1016/j.joms.2020.05.026

13. Louie PK, Harada GK, McCarthy MH, Germscheid N, Cheung JP, Neva MH, El-Sharkawi M, Valacco M, Sciubba DM, Chutken NB, An HS. The impact of COVID-19 pandemic on spine surgeons worldwide. Global Spine J. 2020 May 6:2192568220925783.

14. Hong S, Ai M, Xu X, Wang W, Chen J, Zhang Q, Wang L, Kuang L. Immediate Psychological Impact on Nurses working at 42 government-designated Hospital During COVID-19 Outbreak in China: a cross-sectional study. Nursing Outlook. 2020 Jul 19.

15. Desouky E. Impact of COVID-19 on Urologists: Learning on the Go. Eur Urol Focus 2020. https:// doi. org/10.1016/j.euf.2020.04.008

CONFLICT OF INTEREST: Authors declare no conflict of interest

GRANT SUPPORT AND FINANCIAL DISCLOSURE: NIL

\section{AUTHOR'S CONTRIBUTION}

Following authors have made substantial contributions to the manuscript as under

Ahmed F: Idea, proposal writing, literature review, paper writing

Ali S: Data collection, review, statistical analysis

Kashif L: Conceptualization, proposal writing and review

Sethi A: Critical review, validation

Mahboob U: Critical review, validation

Anwar K: Data collection.

Authors agree to be accountable for all aspects of the work in ensuring that questions related to the accuracy or integrity of any part of the work are appropriately investigated and resolved. 